\title{
KRISTOLOGI OA MATA MUSAN: Kajian Kristologi dalam Budaya Tetun
}

\author{
Jeni Isak Lele, Santriana A. Luruk, Yanti E. Sole, Ezra Tari \\ Institut Agama Kristen Negeri Kupang
}

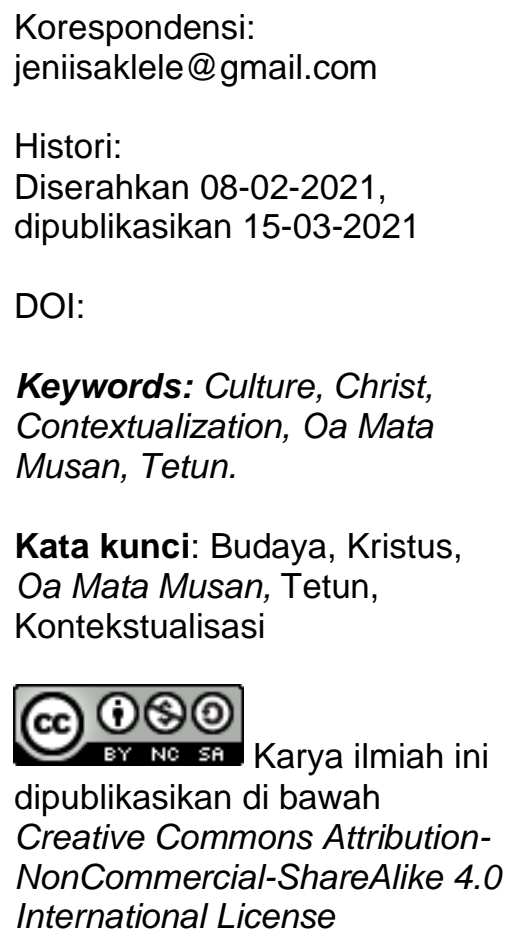

Kata kunci: Budaya, Kristus, Oa Mata Musan, Tetun, Kontekstualisasi dipublikasikan di bawah Creative Commons AttributionNonCommercial-ShareAlike 4.0 International License

Abstract. The understanding of Christ in local customs and culture is still very minimal. Christ has been known only from the western face. Discussions around the nature of Jesus as God or man. There are several writings on Christology in culture, for example, wayang in Javanese culture. Papuan also knew Jesus is known as the Reconciler. In Toraja, Jesus is known as Pangala Tondok. So the author wants to offer one of the Christologies in the Tetun culture. This research explores the Belu people's lives, especially in performing the oa mata musan ritual. This paper does not address the theological debate about the nature of Jesus. However, this study discusses how local people can understand Jesus in their existence. The research method used by the author is phenomenology. Phenomenology is used as a tool to understand facts in the field. This paper contains an offer to the Belu people regarding how they know Christology through their custom. They can realise Christ incarnate in the form of Oa Mata Musan. Oa Mata Musan as a mediator or mediator for conflicting families. Thus Jesus is present as a

peacemaker.

\begin{abstract}
Abstrak. Pemahaman mengenai Kristus dalam adat dan budaya setempat masih sangat minim. Kristus selama ini dikenal hanya dari wajah barat. Diskusi diseputar hakikat Yesus itu Allah atau manusia. Ada beberapa tulisan mengenai Kristologi dalam budaya, misalnya, wayang dalam budaya Jawa. Di Papua, Yesus dikenal sebagai sang Rekonsiliator. Di Toraja, Yesus dikenal sebagai Pangala Tondok. Jadi penulis ingin menawarkan salah satu Kristologi dalam budaya Tetun. Penelitian ini menelusuri kehidupan masyarakat Belu, terutama dalam melakukan ritual oa mata musan. Tulisan ini tidak membahas perdebatan teologis mengenai hakikat Yesus. Namun kajian ini membahas mengenai masyarakat lokal dapat memahami Yesus dalam keberadaan mereka. Metode penelitian yang dipakai penulis adalah fenomenologi. Fenomenologi dipakai sebagai alat untuk memahami fakta yang ada di lapangan. Tulisan ini memuat tawaran pada warga Belu mengenai pemahaman Kristologi dalam adat. Kristus yang berinkarnasi bisa dimengerti dalam wujud Oa Mata Musan. Oa Mata Musan sebagai mediator atau penengah bagi keluarga yang berkonflik. Demikian Yesus hadir sebagai pembawa damai.
\end{abstract}




\section{PENDAHULUAN}

Kristologi budaya hadir pada diskusi ilmu sebagai upaya kontekstualisasi sudah terjadi beabad-abad. Diskusi tentang dasar pengorbanan telah memainkan peran sentral dalam semua agama dan masyarakat saat ini.(Schwager dan Palaver 2018) Secara epistemologis, Kristologi selalu dari bawah karena Yesus sebagai Anak Allah dan misteri penyelamatan yang dilakukan-Nya.(Weinandy 2020) Konsep Kristologis inkarnasional torrance, yaitu, anypostasis dan enhypostasis, hubungan erat antara doktrin penciptaan, penebusan, dan penafsiran sejarah penebusan Israel dari perspektif inkarnasi mengonfigurasikan bahwa dalam inkarnasi, Tuhan di dalam Kristus sepenuhnya mengidentifikasi dengan seluruh umat manusia dan menyelamatkan mereka dari kedalaman ontologis keberadaan mereka.(V. Magezi dan Magezi 2017)

Inkarnasi dilakukan oleh pribadi ilahi dari Logos. Komunikasi antara kodrat terjadi dalam satu arah tetapi tidak di arah lain.(Holmes 2019) Orang Afrika melihat Kristologi dari perspektif leluhur pemujaan leluhur.(C. Magezi dan Igba 2018) Dalam kitab Injil, Yesus menyebut dirinya Anak Manusia setidaknya 80 kali. Yesus memiliki silsilah dan keluarga yang dicatat di Injil Matius dan Lukas. Pada Lukas 2 dicatat Yesus memiliki keluarga yang taat terhadap Hukum Taurat.(Yuliati dan Santoso 2020)

Ada pendekatan konstruksi Kristologi sintesis yang menghubungkan dan menggabungkan pendekatan Kristologi dari atas dan dari bawah ke atas. Karena kedua pendekatan tersebut saling 
mendukung untuk menggambarkan pribadi Yesus.(Harefa, Paath, dan Pasaribu 2019) Pemikiran Kristologi terus berkembang, memasuki abad ke-20, salah satu perkembangan Kristologi yang menarik adalah Kristologi fungsional. Menurut Erickson, penekanan pada Kristologi fungsional mengenai apa yang dilakukan Yesus, bukan siapa Yesus itu.(Purdaryanto dan Siahaan 2020)

Kristologi telah mengalami transformasi dari budaya barat kepada konteks masyarakat lokal. Kontekstualisasi budaya dapat dilakukan kisah tentang kehidupan Yesus, termasuk peristiwa salib dan kebangkitan, dapat diberikan makna oleh masyarakat lokal.(Janice 2017) Salah satu kearifan yang ditemukan adalah kisah hidup dan karya Peagabega yang sepertinya miripdengan kisah hidup Yesus Kristus.(Sondegau 2017) Ada Kristologi Bahari yang dapat menjadi pertimbangan khusus bagi masyarakat SATAS demi membangun pemahaman yang mendasar tentang siapakah Yesus Kristus yang pada akhirnya pemahaman ini menjadi dasar dan kemudian memberi pengaruh bagi kehidupan religius dan juga dalam kehidupan sosial masyarkat.(Takaliuang 2019) Kristologi Perjanjian Baru mengilustrasikan pelajaran ini tentang tidak adanya teodisi yang lengkap bagi manusia sekarang.(Moser 2018) Ada konsep Yesus Kristus adalah Juru Ruwat manusia. Ruwatan adalah aktivitas dan identitas masyarakat Jawa termasuk dalam pelayanan gereja.(Kristriyanto 2018) Penulis akan memaparkan kontektualisasi Oa 
Mata Musan dalam kebudayaan di masyarakat Belu sebagai upaya memahami Kristus.

\section{METODE PENELITIAN}

Pendekatan yang penulis pakai adalah fenomenologi. Fokus penjelasan metode tersebut dalam penelitian ini, selain mengkaji literatur, ada pengumpulan data dan wawancara kepada partisipan.(Hutahaean, Silalahi, dan Simanjuntak 2020) Studi ini menekankan pada kondisi seseorang menafsirkan cara hidup dari pemahaman mereka. Kajian ini memiliki tujuan mengerti dan mendeskripsikan fakta secara mendalam.(Helaluddin 2018)

Objek fenomenologi yakni, menemukan kebenaran empiris yang dibuktikan melalui wawancara dan analisis, di mana struktur kesadaran merupakan tujuan untuk menemukan sebuah konsep, strategi, metode, dan teori.(Usop 2019) Penelitian fenomenologis ditujukan untuk mengambarkan gejala sosial dan budaya menurut sudut pandang subjek yang diteliti. Asumsinya adalah manusia merupakan makhluk yang memiliki kesadaran, pengetahuan, atas apa yang dilakukannya, serta memiliki tujuan berkenaan dengan perilaku atau tindakannya.(AhimsaPutra 2012) Dalam fenomenologi, Husserl membagi tiga reduksi menghadirkan kemurnian dari sesuatu. Adapun ketiga reduksi tersebut 
yaitu reduksi fenomenologis, reduksi eidetis, dan reduksi transcendental.(Assingkily, Putro, dan Sirait 2019)

\section{HASIL PENELITIAN}

Budaya tetun, oa mata musan (anak mata biji) adalah kebiasaan yang telah diturunkan dari generasi ke generasi oleh orang tetun (Malaka). Tradisi ini merupakan sebuah adat yang tidak dapat dipisahkan dari kehidupan orang tetun atau adat wesey-wehali. Adat oa mata musan (anak mata biji) sejak dulu sudah ada, dan tidak dapat dipisahkan dari budaya tetun. Oa mata musan (anak mata biji) merupakan suatu penghargaan yang di milik dalam keluarga. Jadi diwariskan secara turun temurun.

Berdasarkan adat orang tetun, laki-laki dalam keluarga perempuan laki-laki tidak mempunyai hak apa-apa dalam keluarga. Karena perempuan sebagai pemilik harta orang tua. Oa mata musan merupakan suatu pemersatu dalam keluarga. la menjaga hubungan keluarga.

Oa mata musan (anak mata biji) hadir supaya hubungan keluarga tidak putus. Peristiwa pemberian Oa mata musan (anak mata biji) berdasarkan pada pepatah leluhur adalah anin na kis-na kisn onan Nadois na lao ro malae, nakis nala'o ro malae na lao no ba fatu mean leten. Nadai no bafatu mea leten. Too fatuk mea leten lubuh rai nanaranrai nanaran. Te rai nanaran fore nurak akani rai nanaran. Angin sepoi- 
sepoi mengiring perahu menujuh bukit Fatukmea di bukit Fatumea sambil memberi tanda pada hasil yang dicapai dalam bentuk kiasan kacang hijau muda.

Anak kepada keluarga laki-laki (mane) merupakan suatu ikatan dalam keluarga. Oa mata musan (anak mata biji) merupakan sumber persaudaraan. Oa mata musan (anak mata biji) keluarga tetap bersatu. la pemikat kedua keluarga dan sumber persaudaraan. la pemikat kedua keluarga. Adat wesay-wehali tetun adalah norma pelestarian budaya adat agar budaya tidak punah. Anak-anak tetap menghormati, menghargai dan mencintai orang tuanya yang sudah meninggal. la sebagai sumber pemikat keluarga. Nilai oa mata musan (anak mata bij) yakni simbol saling menghormati keluarga laki-laki (mane). Untuk saling menjaga, menghargai sesama keluarga. Sebagai sumber pemikat keluarga.

Oa mata musan sebagai jembatan dalam keluarga anak tersebut akan kasih kembali kepada ibu kandungnya ketika anak tersebuh sudah berkeluarga dan mempunyai anak. Oa mata musan (anak mata biji sebagi jembatan dalam keluarga anak tersebut akan kasih kembali kepada ibu kandungnya ketika anak tersebut sudah berkeluarga dan mempunyai anak. 


\section{PEMBAHASAN}

\section{Adat Istiadat Belu}

Masyarakat hukum adat di NusaTenggara Timur (NTT) hanya mengenal dua sistem adat perkawinan yaitu; sistem perkawinan patrilineal dan matrilineal. Budaya Kabupaten Belu dibentuk dari berbagai unsur yang unik yakni, agama, politik, adat istiadat, bahasa, pakaian, bangunan, dan karya seni.(Tafui 2017) Sistem hukum adat perkawinan matrilineal hanya terdapat dua kabupaten yaitu Kabupaten Belu teristimewa Belu bagian selatan dan Kabupaten Ngada khusus dibajawa kota. Masing-masing sistem hukum adat perkawinan memiliki karakter khas. Masyarakat Belu sangat percaya pada nenek moyang atau leluhurnya dan selalu patuh pada norma-norma yang berasal dari leluhur.(Retnowati 2018)

Di pihak sang istri wajib menyerahkan salah seorang anak yang menjadi orang tua sang suami/ayah apabila salah satunya meninggal dunia (seorang ayah/ seorang ibu). Anak yang dimaksud dalam bahasa adat disebut Oa mata musan. Oa-mata-musan artinya anak pengganti biji mata, (anak penggati ayah) yakni anak yang diserakan oleh pihak keluarga istri kepada pihak keluarga atau kerabat suami dengan tujuan untuk mempercepat tali hubungan antara dua rumpun keluarga atau uma (rumah) suku untuk sang suami. Di samping itu ada juga tujuan lain yakni sebagai tebusan terhadap segala harta kekayaan suami-istri yang di 
wariskan kepada keturunan suami. Anak semacam ini berkedudukan sebagai uma-nain atau tuan rumah dan mempunyai hak yang sama dengan anak-anak lain terhadap semua harta kekayaan bersama dari rumah ayahnya. Dia juga di pertahankan sebagai uma-nain atau tuan rumah.

Paradigma sistem tersebut di jiwa oleh sejumlah nilai filosofis seperti nilai cinta kasih, persatuan dan kesatuan, kedamaian, keharmonisan, nilai religius, kedudukan martabat pribadi wanita sebagai simbol/tanda dewi kesuburan bumi yang memiliki kekuatan sakral gaib yang dikenal sebagai bahasa adatnya sebagai liurai lotu (liurai feto) penguasa bumi. Itulah sebabnya wanita di yakini sebagai sumber kegaiban pendingin kesaktian yang dimiliki oleh seorang Pendekar/Meo. Dan sekaligus sebagai imam yang bertugas mempersembahkan semua bentuk ritual adat dengan menggunakan sirih-pinang di atas loteng sakral di bawah tiang agung rumah adat (rumah pemalih/Uma Lulik). Itulah sebabnya laki-laki harus meninggalkan orang tuanya untuk pergi bersatu dengan sang istri di rumah kediaman sang istri (paradigma sistem hukum adat perkawinan matrilineal). Sistem tersebut sangat sesuai dengan rasa keadilan, kepastian hukum dan kebahagiaan masyarakat hukum adat yang bersangkutan. 


\section{Kristologi Oa Mata Musan}

Yesus hadir sebagai wujud keramahan Allah dan menjadi model bagi komunitasnya. Kristologi Lukas menghadirkan gagasan keramahan Allah. Kontribusi ini sangat penting dalam membangun model kehidupan kekristenan dalam konteks Indonesia.(Manurung 2018) Di masyarakat Jawa, gaya wayang purwa lebih dirasakan sebagai identitas ketimbang gaya arca.(Paskalis 2017) Kristologis hadir dalam masalah sosial-politik dan pemiskinan. Dinamika diskusi di atas, ada tawaran mengenai Yesus Pembebas.(Mulait 2019) Konsep kristologis Nabi zaman akhir berlaku untuk panggilan Yesus di bumi yang disajikan dalam Perjanjian Baru, tetapi konsep itu hanya menggambarkan satu sisi saja dari karya ini, yaitu kegiatan pengabaran dan penyembuhan Yesus.(Wicaksono dan Anggono 2019)

Penulis menawarkan sebuah Kristologi yang dibangun dari kebudayaan. Pendekatan Kristologi dalam kebudayaan adalah upaya kontekstualisasi dengan tetap berpedoman pada Alkitab.(Panjaitan dan Siburian 2019) Oa-mata-musan adalah anak yang diserakan oleh pihak keluarga istri kepada pihak keluarga atau kerabat suami dengan tujuan untuk mempercepat tali hubungan antara dua rumpun keluarga atau uma (rumah) suku untuk sang suami. Oa Matamusan menempati posisi ayahnya dan mendapatkan semua hak ayahnya dalam keluarga.(Bria, Sujito, dan G.Sriningsih 2014) Di samping itu ada tujuan lain yakni sebagai 
tebusan terhadap segala harta kekayaan suami-istri yang di wariskan kepada keturunan suami. Anak semacam ini berkedudukan sebagai umanain atau tuan rumah dan memiliki hak yang sama dengan anak yang lain terhadap semua harta kekayaan bersama dari rumah ayahnya. Dia di pertahankan sebagai uma-nain atau tuan rumah.

Yesus hadir di dunia merupakan inkarnasi Allah. Tuhan menjadi daging dan ada di antara manusia. Perkataan tersebut membuat identitas Yesus sebagai manusia berada dalam waktu dan tempat yang terbatas. la adalah realitas transenden dari keberadaan Allah sendiri.(Macaskill 2018) Kemudian Allah hadir meninggalkan kemuliaan dari keadaan-Nya yang sebelumnya, untuk menggunakan kain kotor berupa kodrat manusia.(Rouw dan Sugiono 2019) la berada di tengah tidak layak mendapat perhatian. Mesias tidak mendahulukan mereka yang memiliki kekuasaan, atau bahkan mereka yang kebutuhannya tampak lebih mendesak. Ini sangat mencolok ketika seseorang menganggap-Nya dalam Markus dan Lukas, putri Yairus belum meninggal ketika wanita itu menghentikan Yesus (Mrk.5:28-30).(Dinkler 2017)

Konteks kesengsaraan dan penderitaan di Asia, Yesus diharapkan hadir sebagai pembebas sejati. Dia membebaskan baik spiritual maupun fisik.(Athappilly 2017) Dalam konteks rasisme di Amerika, Cone percaya kulit hitam dan kulit putih dapat berekonsiliasi dalam dua kondisi yakni, pertama pembebasan yang tertindas. Kedua, penegasan martabat hitam. 
Jadi rekonsiliasi adalah anugerah Tuhan tentang kegelapan bagi kulit putih, dan pembebasan adalah anugerah Tuhan untuk orang-orang AfrikaAmerika yang tertindas.(Watters 2019) Kemudian penghayat kebatinan memahami 'Yesus Kristus Sang Jalan' merupakan tonggak pemersatu antara kearifan lokal dan ajaran iman Katolik.(Lelono, Martinus 2015)

Masyarakat Papua menghayati sosok Yesus sebagai Sang Penyelamat. Beberapa di antaranya adalah: Yesus sebagai Peagabega, Yesus sebagai Nourekul, Yesus sebagai Koyeidaba, Yesus sebagai Mobubokouto (Sumber Kehidupan) dan Yesus sebagai Ipa Bokouto (Sang Pengasih).(Kayame 2019)

Penulis telah menjelaskan di atas bahwa oa mata musan adalah anak yang memiliki tanggung jawab besar terhadap keluarga. la adalah pemilik hak waris orang tuanya. la sebagai pengikat keluarga besar. Kehadiran anak ini sangat penting dalam keluarga, karena tanpa kehadirannya keluarga akan saling berebut harta warisan. Demikian Yesus disebut sebagai pewaris Kerajaan Allah, yang menempati peringkat pertama. la ada sebelum segala sesuatu ada.(Aliyanto 2019) Jika manusia digambarkan sebagai pengantin perempuan, maka Yesus sang oa mata musan adalah jalan atau pengikat antara Allah dan manusia. Kehadiran-Nya sebagai penghormatan kepada Allah.

Yesus sang anak mata biji hadir memberikan teladan untuk dikerjakan dan ditiru oleh para murid-Nya. Contoh pekerjaan itu adalah 
kerelaan melayani bukan sebagai yang penting melainkan sebagai hamba (Luk. 22:24-27).(Giawa 2019) Pengertian dan penekanan seorang Oa mata musan menjadi contoh dalam keluarga dengan mempertanggungjawabkan apa yang telah dilakukan kepada Tuhan Pemberi hidup.(Rumahorbo 2020) Dalam inkarnasi-Nya, Yesus mengambil bagian dalam penderitaan manusia, menanggung beban manusia dan mempersatukan manusia dengan Allah.(Harefa 2020)

Seseorang dituntut untuk memberi teladan seperti Yesus ketika mengalami berbagai penderitaan. Ketabahan dalam menghadapi situasi tersebut akan membawa pada keserupaan dengan Yesus.Keserupaan merupakan bagian penting dalam persekutuan dengan Yesus. (Bora 2020) Jika disejajarkan dengan kepribadian gembala, oa mata musan dapat menjadi panutan proses belajar mengajar sebagai pendidik dalam masyarakat.(Puspito 2021) Karena ia hadir sebagai pendamaian antara Allah dan manusia yang berdosa menjadi inisiator dan pelaku dalam membangun dan melestarikan alam.(Sitohang 2019) Yesus hadir sebagai mediator yang mendekap umat di tengah krisis gerejagereja. Jika oa mata musan sebagai perekat dan mediator seperti Kristus yang dapat mempersatukan gereja secara batin.(Kantohe dan Hakh 2020) Kristus hadir bukan saja Juruselamat pribadi manusia, tetapi alam semesta.(Stepanus 2019) Karena itu gereja perlu mengadakan wawan 
rembug dalam proses bersama dengan Allah serta menentukan tindakan apa yang harus dilakukan dan peran yang dilakukan.(Antonius 2016)

\section{KESIMPULAN}

Penulis menawarkan kepada masyarakat Belu mengenai kontekstualisasi Kristologi dalam adat. Kristus yang berinkarnasi dapat dipahami dalam sosok Oa Mata Musan. Oa Mata Musan hadir sebagai pererat keluarga. Demikian Kristus sebagai jalan pengikat antara Allah dan manusia. la ahli waris keluarga. la mendamaikan keluarga besar jika terjadi perselisihan. Sama seperti Kristus hadir dalam dunia untuk mendamaikan manusia dengan Allah. la mendamaikan manusia yang bersengketa. la adalah ahli waris kerajaan Allah.

\section{DAFTAR PUSTAKA}

Ahimsa-Putra, Heddy Shri. 2012. "Fenomenologi Agama: Pendekatan fenomenologi untuk memahami Agama." Walisongo: Jurnal Penelitian Sosial Keagamaan 20 (2): $271-304$. https://doi.org/10.21580/WS.20.2.200.

Aliyanto, Deky Nofa. 2019. "Tanggapan Terhadap Kristologi Saksi Yehuwa Kristus adalah Ciptaan Yang Pertama Berdasarkan Kolose 1:15." FIDEl: Jurnal Teologi Sistematika dan Praktika 2 (2): 244-361. https://doi.org/10.34081/fidei.v2i2.39.

Antonius, Kurnia Andrianto. 2016. "Pergumulan Kebatinan Jawa Memaknai Kehadiran Yesus Kristus." Jurnal Teologi 5 (1): 15-26. https://doi.org/10.24071/jt.v5i1.478.

Assingkily, Muhammad Shaleh, Khamim Zarkasih Putro, dan Sangkot Sirait. 2019. "Kearifan Menyikapi Anak Usia Dasar di Era Generasi Alpha (Ditinjau dari Perspektif Fenomenologi)." Attadib: Journal of $\begin{array}{llll}\text { Elementary Education } & 3 & \text { (2): } & \text { 1-21. }\end{array}$ https://doi.org/10.32507/ATTADIB.V312.572.

Athappilly, Sebastian. 2017. "Asian Christology: Some Stray Reflection." 
Asian Horizons 11 (4): 615-33.

Bora, Lewi Nataniel. 2020. "Keserupaan Dengan Yesus Dalam Penderitaan, Kesengsaraan Dan Kematian-Nya." Manna Rafflesia 7 (1): 65-89. https://doi.org/10.38091/man_raf.v7i1.127.

Bria, Roswita Nelviana, Sujito, dan Maria G.Sriningsih. 2014. "Customary Law Toward Matamusan Dertermination to Custom Society at Wewiku Wehali, Belu, NTT." Jurnal IImiah Bahasa dan Sastra 1 (1): 94-112.

Dinkler, Michal Beth. 2017. "A new formalist approach to narrative christology: Returning to the structure of the synoptic gospels." HTS Teologiese Studies / Theological Studies 73 (1): 1-11. https://doi.org/10.4102/hts.v73i1.4801.

Giawa, Nasokhili. 2019. "Serving Others: Keteladanan Pelayanan Yesus Kristus Berdasarkan Yohanes 13." Integritas: Jurnal Teologi 1 (1): 54 65. https://doi.org/10.47628/ijt.v1i1.9.

Harefa, Febriaman Lalaziduhu. 2020. "Menggunakan Konsep Inkarnasi Yesus sebagai Model Penginjilan Multikultural." PASCA: Jurnal Teologi dan Pendidikan Agama Kristen 16 (1): 50-61. https://doi.org/10.46494/psc.v16i1.75.

Harefa, Febriaman Lalaziduhu, Jeane Paath, dan Ferdinan Pasaribu. 2019. "Konstruksi Kristologi Di Bumi Indonesia." SCRIPTA: Jurnal Teologi dan Pelayanan Kontekstual 7 (1): 85-98. https://doi.org/10.47154/SCRIPTA.V7I1.62.

Helaluddin. 2018. "Mengenal Lebih Dekat dengan Pendekatan Fenomenologi: Sebuah Penelitian Kualitatif."

Holmes, Stephen R. 2019. "Asymmetrical assumption: Why Lutheran christology does not lead to kenoticism or divine passibility." Scottish $\begin{array}{lllll}\text { Journal of Theology } 72 & \text { (4): }\end{array}$ https://doi.org/10.1017/S0036930619000589.

Hutahaean, Hasahatan, Bonnarty Steven Silalahi, dan Linda Zenita Simanjuntak. 2020. "Spiritualitas Pandemik: Tinjauan Fenomenologi Ibadah Di Rumah." Evangelikal: Jurnal Teologi Injili dan Pembinaan Warga Jemaat 4 (2): 235-50. https://doi.org/10.46445/ejti.v4i2.270.

Janice, Nyssa. 2017. "Kristologi Feminis." Indonesian Journal of Theology 4 (2): 172-93. https://doi.org/10.46567/ijt.v4i2.39.

Kantohe, Finki Rianto, dan Samuel Benjamin Hakh. 2020. "Yesus Sang Mediator yang Merengkuh Umat Termarginalisasi: Sebuah Analisis Sosio-Historis Terhadap Yohanes 9." GEMA TEOLOGIKA: Jurnal Teologi Kontekstual dan Filsafat Keilahian 5 (2): 207-22. https://doi.org/10.21460/gema.2020.52.595. 
Kayame, Yohanes. 2019. "Yesus Kristus Menurut Orang Papua." Jurnal Teologi 08 (01): 187-212. https://doi.org/10.24071/jt.v8i2.1920.

Kristriyanto, Kristriyanto. 2018. "Yesus Kristus Juru Ruwat Manusia: Sebuah Pendekatan Semiotika dalam Gereja Kristen Jawa." KURIOS (Jurnal Teologi dan Pendidikan Agama Kristen) 4 (1): 39-55. https://doi.org/10.30995/KUR.V4I1.32.

Lelono, Martinus, Joko. 2015. "Yesus Kristus Sang Jalan: Kristologi Kontekstual Bagi Penghayat Kebatinan Katolik." Jurnal Teologi 4 (2): 107-20. https://doi.org/10.24071/jt.v4i2.469.

Macaskill, Grant. 2018. "Name Christology, Divine Aseity, and the I Am Sayings in the Fourth Gospel." Journal of Theological Interpretation 12 (2): 241. https://doi.org/10.5325/jtheointe.12.2.0217.

Magezi, Christopher, dan Jacob T. Igba. 2018. "African theology and african christology: Difficulty and complexity in contemporary definitions and methodological frameworks." HTS Teologiese Studies/ Theological Studies $74 \quad$ (1): $1-7$. https://doi.org/10.4102/hts.v74i1.4590.

Magezi, Vhumani, dan Christopher Magezi. 2017. "Christ also ours in Africa: A consideration of torrance's incarnational, christological model as nexus for christ's identification with African christians." Verbum et Ecclesia 38 (1): 1-12. https://doi.org/10.4102/ve.v38i1.1679.

Manurung, Frans Styadi. 2018. "Teologi Keramahan Allah: Sebuah Pembacaan Kristologi Lukas." Gema Teologika: Jurnal Teologi Kontekstual dan Filsafat Keilahian 3 (2): 185-206.

Moser, Paul K. 2018. "Theodicy, Christology, and Divine Hiding: Neutralizing the Problem of Evil." The Expository Times 129 (5): 191200. https://doi.org/10.1177/0014524617743183.

Mulait, Meki. 2019. "Mengimani Yesus Kristus Sang Pembebas: Suatu Upaya Berkristologi dalam Konteks Pemiskinan Gereja Indonesia." Studia Philosophica et Theologica 18 (1): 71-91. https://doi.org/10.35312/spet.v18i1.24.

Panjaitan, Firman, dan Hendro H. Siburian. 2019. "Misi Kristologi Dalam Konteks Kebudayaan ." LOGIA: Jurnal Teologi Pentakosta 1 (1).

Paskalis, Bayu Edvra. 2017. "Membangun Kristologi Melalui Seni Rupa Kristus Tersalib Gaya Wayang Purwa." Jurnal Teologi 06 (1): 17-38. https://doi.org/10.24071/JT.V6I1.988.

Purdaryanto, Samuel, dan Frendi Erixson Siahaan. 2020. "Deskripsi Historis Doktrin Kristologi." Sesawi: Jurnal Teologi dan Pendidikan Kristiani 2 (1): 156-69. 
Puspito, Indro. 2021. "Yesus Sebagai Model Gembala Sejati dan Relasinya Terhadap Gembala Sebagai Pendidik." Excelsis Deo: Jurnal Teologi, Misiologi, dan Pendidikan 4 (2): 87-106.

Retnowati, Endang. 2018. "Makna Budaya Tradisional Belu bagi Multikulturalisme." Jurnal Masyarakat dan Budaya 19 (2): 175. https://doi.org/10.14203/jmb.v19i2.504.

Rouw, Julian Frank, dan Sugiono. 2019. "Syair Kristologi Tentang KeAllah-An Yesus Dalam Filipi 2:6-11." Jurnal Teologi dan Pendidikan Kristen) 1 (2): 140-54.

Rumahorbo, Herlince. 2020. "Keteladanan Tanggung Jawab Yesus Sebagai Gembala Menjadi Dasar Pelayanan Hamba Tuhan Masa Kini." Phronesis: Jurnal Teologi dan Misi 3 (2): 130-46. https://doi.org/10.47457/phr.v3i2.68.

Schwager, Raymund, dan Wolfgang Palaver. 2018. "Christology." In The Wiley Blackwell Companion to Political Theology, 389-402. Chichester, UK: John Wiley \& Sons, Ltd. https://doi.org/10.1002/9781119133759.ch28.

Sitohang, Binsan. 2019. "Manusia dalam Kondisi Diperdamaikan dengan Allah." ASTEROS: Jurnal Teologi dan Pendidikan Kristen 8 (1): 5464.

Sondegau, Kleopas. 2017. "Kristologi dalam Konteks Kebudayaan Suku Migan di Papua." Studia Philosophica et Theologica 17 (1): 60-79. https://doi.org/10.35312/SPET.V1711.38.

Stepanus. 2019. "Keunggulan Yesus Kristus Menurut Kolose 1:16-18." HUPERETES: Jurnal Teologi dan Pendidikan Kristen 1 (1): 49-61. https://doi.org/10.46817/huperetes.v1i1.16.

Tafui, Steavan Stasia. 2017. "Aplikasi Pengenalan Kebudayaan Kabupaten Belu Berbasi Android." Jurnal Mahasiswa Teknik Informatika) 1 (2): 61-66.

Takaliuang, Jammes Juneidy. 2019. "Kristologi Bahari." Missio Ecclesiae 8 (1): 1-16.

Usop, Tari Budayanti. 2019. Kajian Literatur Metodologi Penelitian Fenomenologi dan Etnografi. https://doi.org/10.13140/RG.2.2.15786.47044.

Watters, Kelsi. 2019. "Solidarity and Suffering: Liberation Christology from Black and Womanist Perspectives." Obsculta 12 (1): 78-107.

Weinandy, Thomas G. 2020. "Frank D.Macchia, Jesus the Spirit Baptizer: Christology in Light of Pentecost. Grand Rapids: Eerdmans, 2018, xi + 371pp. \$48.00." International Journal of Systematic Theology 22 (1): 
140-43. https://doi.org/10.1111/ijst.12371.

Wicaksono, Arif -, dan Dwi Anggono. 2019. "Yesus, Hamba Allah Yang Menderita." FIDEl: Jurnal Teologi Sistematika dan Praktika 2 (1): 142-58. https://doi.org/10.34081/fidei.v2i1.44.

Yuliati, dan Stanley Santoso. 2020. "Pengaruh Pendidikan Agama Kristen Dalam Peningkatan Pemahaman Mahasiswa Kristen Tentang Kristologi Alkitabiah." Jurnal Gamaliel: Teologi Praktika 2 (1): 11-19. https://doi.org/10.38052/gamaliel.v2i1.49. 